
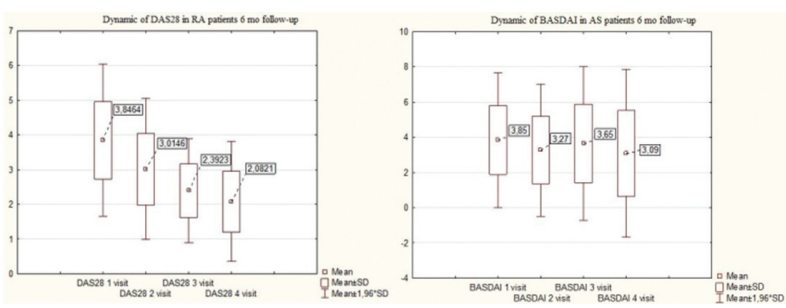

Conclusions: Therefore, the preliminary results show good tolerability and efficacy of inactivated split-virus influenza vaccine in RA, AS, and SS patients. Future studies on larger patients' populations are warranted for more complete evaluation of vaccine safety and efficacy.

Disclosure of Interest: None declared

DOI: 10.1136/annrheumdis-2018-eular.1500

\section{SAT0396 THE RISK FACTORS OF SERIOUS INFECTION IN PATIENTS WITH RHEUMATOID ARTHRITIS}

E. Hasegawa ${ }^{1,2}$, D. Kobayashi ${ }^{1}$, S. Ito ${ }^{1}$, I. Narita ${ }^{2}$, K. Nakazono ${ }^{1} .{ }^{1}$ Department of Rheumatology, Niigata Rheumatic Center, Shibata; ${ }^{2}$ Division of Clinical Nephrology and Rheumatology, Niigata University Graduate School of Medical and Dental Sciences, Niigata, Japan

Background: Although life expectancy has improved for many rheumatoid arthritis (RA) patients, serious infection is one of the major causes of mortality. Undernutrition is widely known to be a risk factor for infection; however, the association between undernutrition and infection in RA patients is not well known.

Objectives: The aim of this study was to identify the risk factors associated with infection requiring hospitalisation in $\mathrm{RA}$ patients.

Methods: We retrospectively analysed data obtained from 74 patients with RA (male, $\mathrm{n}=21$; female, $\mathrm{n}=53$; age $74.7 \pm 12.6$ ), who were admitted to our hospital between 2016 and 2017 for infection (infection group). Among the patients who experienced multiple infections during this time, only the first infection was included in this study. We also recruited control RA patients $(n=222)$ who were matched for age, gender and disease duration, with a match ratio of 1:3 (noninfection group). The details of the patients' infections, clinical characteristics (including nutritional conditions), and RA treatment were obtained from their clinical records. The nutritional condition was assessed based on the body mass index (BMI), serum albumin (Alb) level, total lymphocyte count (TLC), haemoglobin $(\mathrm{Hb})$ level, controlling nutrition status (CONUT) score, and prognostic nutritional index (PNI). Differences between each group were compared using a nonparametric Wilcoxon's rank sum test for continuous variables and Fisher's exact test for categorical variables. Multiple regression analyses were performed to determine the factors associated with the development of serious infection. We selected seven candidate factors: Steinbrocker's classification (Stage) $\geq$ III, $\mathrm{BMI} \geq 18.5$, CONUT score $\geq 5$, DAS28-ESR $\geq 3.2$, use of methotrexate, use of prednisolone, use of biologics.

Results: The respiratory tract was the most frequent site of infection $(n=33$, $44.6 \%)$, followed by the urinary tract $(n=14,18.9 \%)$, skin $(n=13,17.6 \%)$, bones and joints $(n=5,6.8 \%)$, and gastrointestinal tract $(n=3,4.1 \%)$. Seven patients died during hospitalisation for infection, in spite of treatment. Relative to the non-infection group, the BMI $(20.9 \pm 4.1$ vs. $22.0 \pm 3.4, p=0.036)$, Alb $(3.3 \pm 0.7$ vs. $3.9 \pm 0.4 \mathrm{~g} /$ $\mathrm{dL}, \mathrm{p}<0.001)$, TLC ( $1190 \pm 574$ vs. $1328 \pm 526 / \mu \mathrm{L}, \mathrm{p}=0.008), \mathrm{Hb}(11.1 \pm 1.9$ vs. 12.3 $\pm 1.5 \mathrm{~g} / \mathrm{dL}, \mathrm{p}<0.001)$, and $\mathrm{PNI}(55.4 \pm 8.0$ vs. $60.4 \pm 8.0, \mathrm{p}<0.001)$ values were significantly lower, and the CONUT score (4.1 \pm 2.7 vs. $1.9 \pm 1.5, p<0.001)$ was significantly higher in the infection group. In addition, the DAS 28 -ESR (3.5 \pm 1.2 vs. 2.9 $\pm 1.1, p=0.001)$, dose of prednisolone $(4.6 \pm 3.4$ vs. $2.3 \pm 2.3, p<0.001)$, and rate of biologics usage ( 33.8 vs. $21.2 \%, p=0.041)$ were higher, while the dose of methotrexate (1.6 \pm 3.2 vs. $3.2 \pm 4.0, p=0.002)$ was lower in the infection group. The multiple regression analysis revealed that the CONUT score (odds ratio [OR], 62.9; $95 \%$ credible interval [Crl], 7.9 to 500.0 ), use of prednisolone (OR, 6.7; $\mathrm{Crl}, 2.2$ to 20.7), and use of biologics (OR, 3.9; $\mathrm{Crl}, 1.7$ to 9.3 ) were significant risk factors for serious infection.

Conclusions: Multiple factors were found to be associated with infection in RA patients. The improvement of nutrition may have a beneficial effect with regard to the prevention of infection during the care of RA patients.

Disclosure of Interest: None declared

DOI: 10.1136/annrheumdis-2018-eular.3839

\section{SAT0397 SAFETY AND IMMUNOGENICITY OF 23-VALENT PNEUMOCOCCAL VACCINE IN SLE PATIENTS}

G. Tarasova, B. Belov, D. Bukhanova, S. Soloviev, E. Aseeva, T. Popkova, M. Cherkasova. V.A. Nasonova Research Institute of Rheumatology, Moscow, Russian Federation

Background: Immunisation with pneumococcal vaccine is the key prophylactic measure to protect patients with systemic lupus erythematosus (SLE) against severe respiratory infections.

Objectives: To study the efficacy and immunogenicity of 23-valent polysaccharide pneumococcal vaccine in SLE pts.

Methods: The study included 30 SLE pts, 27 females, 3 males, aged 19-62 y, the follow up (FUP) was $12 \mathrm{mo}$. Disease activity at vaccination was high - in 1 patient, moderate - in 4 pts, and low - in 20 pts; drug-induced remission - in 5 . Therapy: 29 pts were on glucocorticoids (GCs), 23 - on hydroxychloroquine, 14 on cytostatic (CS) drugs, 9 - on biologic diseases modifying anti rheumatic drugs (bDMARDs): 4 - on rituximab, and 5 - on belimumab. One dose $(0,5 \mathrm{~mL})$ of 23 valent polysaccharide pneumococcal vaccine was administered subcutaneously. Standard clinical examination and lab tests were performed, and vaccine immunogenicity was determined by measuring antibody (AB) levels against Streptococcus pneumoniae (VaccZymeTM PCP IG 2 panels (The Binding Site Ltd, Birmingham, UK)) at control visits.

Results: Local injection site reactions of varying intensity were registered in 19 $(63,3 \%)$ pts, lasting from 2 to 7 days. One patient developed an immediate hypersensitivity reaction - the Arthus phenomenon-type. All accompanying symptoms completely resolved within 7 days with the intake of antihistaminic drug and local use of GCs. Mean (Me (25,75 percentiles)) SLEDAI scores for SLE activity prior to and 1 year after vaccination did not differ significantly: $2(2 ; 4)$ and $2(0 ; 4)$, respectively. Mean values of SLE immunological activity parameters (a-dsDNA, C3 and C4 components of the complement) also did not differ significantly, with a visible trend for a-dsDNA reduction and complement components increase: C3 $(0,86$ $(0,81 ; 1.07)$ and $0,93(0,86 ; 1,05)) ; C 4(0,16(0,13 ; 0,19)$ and $0,18(0,13 ; 0,19)$, respectively. (table 1 )

Abstract SAT0397 - Table 1. Dynamics of immunological activity parameters (Me) and SLE SLEDAI (Me) scores prior to and after the vaccination (12 mo).

\begin{tabular}{|c|c|c|c|c|}
\hline FUP & $\begin{array}{c}\text { A- } \\
\text { dsDNA } \\
<20\end{array}$ & $\begin{array}{c}\text { C3 } \\
0,9-1,8\end{array}$ & $\begin{array}{c}\text { C4 } \\
0,1-0,4\end{array}$ & SLEDAI \\
\hline $\begin{array}{l}\text { Visit } 1 \\
\text { (baseline) }\end{array}$ & $\begin{array}{c}21,3 \\
(4,7 ; 48,4\end{array}$ & $\begin{array}{c}\mathbf{0 , 8 6} \\
(0,81 ; 1,07)\end{array}$ & $\begin{array}{c}\mathbf{0 , 1 6} \\
(0,13 ; 0,19)\end{array}$ & $\begin{array}{c}2 \\
2 ; 4\end{array}$ \\
\hline $\begin{array}{l}\text { Visit } 2 \\
(1 \mathrm{mo})\end{array}$ & $\begin{array}{c}25,0 \\
(4,7 ; 48,4\end{array}$ & $\begin{array}{c}\mathbf{1 , 1} \\
(0,9 ; 1,2)\end{array}$ & $\begin{array}{c}\mathbf{0 , 1 7} \\
(0,13 ; 0,19)\end{array}$ & $\begin{array}{c}2 \\
(0 ; 4)\end{array}$ \\
\hline $\begin{array}{l}\text { Visit } 3 \\
\text { (3 mo) }\end{array}$ & $\begin{array}{c}20,9 \\
\left(^{8,2 ; 34,5}\right.\end{array}$ & $\begin{array}{c}\mathbf{0 , 9 1} \\
(0,8 ; 1,0)\end{array}$ & $\begin{array}{c}\mathbf{0 , 1 7} \\
(0,14 ; 0,2)\end{array}$ & $\begin{array}{c}2 \\
2^{2 ; 4}\end{array}$ \\
\hline $\begin{array}{l}\text { Visit } 4 \\
\text { (12 mo) }\end{array}$ & $\begin{array}{c}18,7 \\
(8,7 ; 68,7\end{array}$ & $\begin{array}{c}\mathbf{0 , 9 3} \\
(0,86 ; 1,05)\end{array}$ & $\begin{array}{c}\mathbf{0 , 1 8} \\
(0,12 ; 0,19)\end{array}$ & $\begin{array}{c}2 \\
(0 ; 4)\end{array}$ \\
\hline
\end{tabular}

There were no SLE exacerbations with definite casual relationship with the vaccination. Significant increase ( $\geq 2$ fold vs the baseline values) of $A B$ levels against S.pneumoniae polysaccharides was documented in $25(83,3 \%)$ pts 1 mo post-vaccination. High AB titers still persisted 1 year post-vaccination in $19(63,3 \%)$ pts (responders). More than 2-fold increase of anti- S.pneumoniae $\mathrm{AB}$ concentrations was not maintained by the end of FUP $(12 \mathrm{mo})$ in $11(36,7 \%)$ «non-responders». $7(63,6 \%)$ out of them were treated with GEBA (4 rituximab, 3 - belimumab). $2(10,5 \%)$ pts out of 19 «responders» were also treated with GEBA (belimumab). The difference was statistically significant, $p=0008$.

Conclusions: Obtained results demonstrate the safety and immunogenicity of 23-valent pneumococcal vaccine in SLE patients during one year FUP. The negative effect of bDMARDs on post-vaccination response was noticed. Future studies of vaccine efficacy and safety are needed in larger SLE populations.

Disclosure of Interest: None declared

DOI: 10.1136/annrheumdis-2018-eular.3663

\section{SAT0398 SPINE IMMOBILISATION AND NEUROLOGICAL COMPLICATIONS IN VERTEBRAL OSTEOMYELITIS: RESULTS FROM A MULTICENTER PROSPECTIVE STUDY}

G. Bart ${ }^{1}$, G. Coiffier ${ }^{2}$, O. Merot ${ }^{3}$, M. Couderc ${ }^{4}$, E. Hoppe ${ }^{5}$, G. Cormier ${ }^{6}$, J.-M. Ziza ${ }^{7}$, B. Le Goff'. ${ }^{1} \mathrm{CHU}$ Nantes, Nantes; ${ }^{2} \mathrm{CHU}$ Rennes, Rennes; ${ }^{3}$ Saint Nazaire Hospital, Saint Nazaire; ${ }^{4} \mathrm{CHU}$ Clermont, Clermont-Ferrand; ${ }^{5} \mathrm{CHU}$ Angers, Angers; ${ }^{6} \mathrm{CHD}$ Vendée, La Roche sur Yon; ${ }^{7}$ GHDCSS, Paris, France

Background: Neurological complications of vertebral osteomyelitis (VO) can be serious. In a previous work, ${ }^{1}$ we showed that they occur in up to $40 \%$ of the 